\title{
Preliminary results on temperature distribution in the Quaternary fluvial and outwash deposits of the Piedmont Po Plain (NW Italy): a statistical approach
}

\author{
Diego Barbero $\left({ }^{a}\right)$, Domenico Antonio De Luca $\left({ }^{a}\right)$, Maria Gabriella Forno $\left(^{a}\right)$ \& Manuela Lasagna $\left({ }^{a}\right)$
}

(a) Department of Earth Sciences, University of Turin, Via Valperga Caluso, 35, 10125, Turin, Italy. E-mail: diego.barbero@unito.it

\begin{abstract}
We propose a statistical approach to the study of subsoil thermal data in order to find an equation able to describe the temperature distribution in the underground of the Piedmont plain sectors (NW Italy). The analytical model here proposed, can be used during the preliminary stage of investigation for the exploitation of subsoil by means of low enthalpy geothermal plants. The statistical analysis was performed using groundwater thermometric data from thermal logs collected in boreholes crossing the Quaternary fluvial deposits hosting a shallow aquifer.
\end{abstract}

KEY WORDS: differential heat equation, fluvial deposits, shallow aquifer, thermal logs, statistical analysis, Piedmont region.

\section{INTRODUCTION}

The aim of this study is to elaborate an equation able to describe the time average distribution of the temperature in the first several meters of the subsurface, developed through a statistical process of optimization based on the "least squares method".

The equation has been developed from theoretical solutions of the heat transfer equation by conduction with stationary boundary conditions. For this purpose, we select the Piedmont Po Plain, where a piezometric monitoring network of the shallow aquifer occurs. The boreholes crossed the Quaternary fluvial and outwash deposits. Because of the geological and hydrogeological differences of the Piedmont plain, the statistical analysis of the thermometric data, was performed separately examining the temperature measures for "geologically homogeneous areas". In this way, we identified four main plain sectors: Turin Po Plain, Vercelli and Novara Po Plain, Alessandria Po Plain and Cuneo and Southern Turin Po Plain.

\section{GEOLOGICAL AND HYDROGEOLOGICAL SETTING}

The subsoil in the Piedmont plain sectors (NW Italy) consists of a succession of superimposed sedimentary complexes represented by marine, deltaic and fluvial sediments (Boni \& Casnedi, 1970; Bonsignore et al., 1969; Irace et al., 2009; Servizio Geologico d'Italia, 1967). The sedimentary succession is defined by deep marine clay deposits, (Lugagnano Clay) with littoral sandy deposits (Asti Sand). The fossil content of both sediments suggests a reference to the Zanclean. The Lugagnano Clay shows some hundreds of meters thick and consists of grayblue clayey silt and sandy marl rich in microfossils. The superimposed Asti Sand consists of not stratified medium-fine grained sand or with horizontal planar lamination. These sediments, of an overall yellow color, appears strongly cemented, particularly where the coastal marine mollusks fossils are abundant. These sediments are usually covered by the "villafranchian succession" comprising deltaic deposits (Lower Complex) and fluvial deposits (Upper Complex), referred to the Piacenzian and Calabrian respectively, separated by an unconformity (Cascina Viarengo Surface) (Forno et al., 2015). Above, a widespread silty and subordinately gravelly fluvial cover of middle and upper Pleistocene occurs. These fluvial deposits are linked to Po and Tanaro ancient river courses and host a shallow aquifer. The shallow aquifer is mainly supplied by direct rainfall and rivers at the outlet of the valleys in the plain. This aquifer has a thickness generally ranging between 20 and $50 \mathrm{~m}$; in spite of the variable thickness of the aquifer, it has a high productivity and has a regional importance. The base of the shallow aquifer is generally well marked due to a textural variability of the deposits. The local presence of thick and relatively continuous layers of silt or clay-rich deposits allows a clear separation between the shallow aquifer, hosted in fluvial deposits, and deep aquifers, hosted mainly in marine and permeable horizons of the villafranchian succession (Bove et al., 2005; Irace et al., 2009).

\section{METHODS}

\section{THERMOMETRIC DATA}

The data were collected in 118 piezometers of the regional monitoring network, during two piezometric surveys (spring and the autumn, 2008) (fig. 1). The thermometric surveys allowed to collect 513 data in the spring and 585 data in the autumn (Balsotti, 2009). The average depth of the piezometers is about 30 up to 50 meters. The measures were obtained by the use of probes equipped with sensors of temperature and depth, with sensitivity of $0.01^{\circ} \mathrm{C}$ on temperature. 


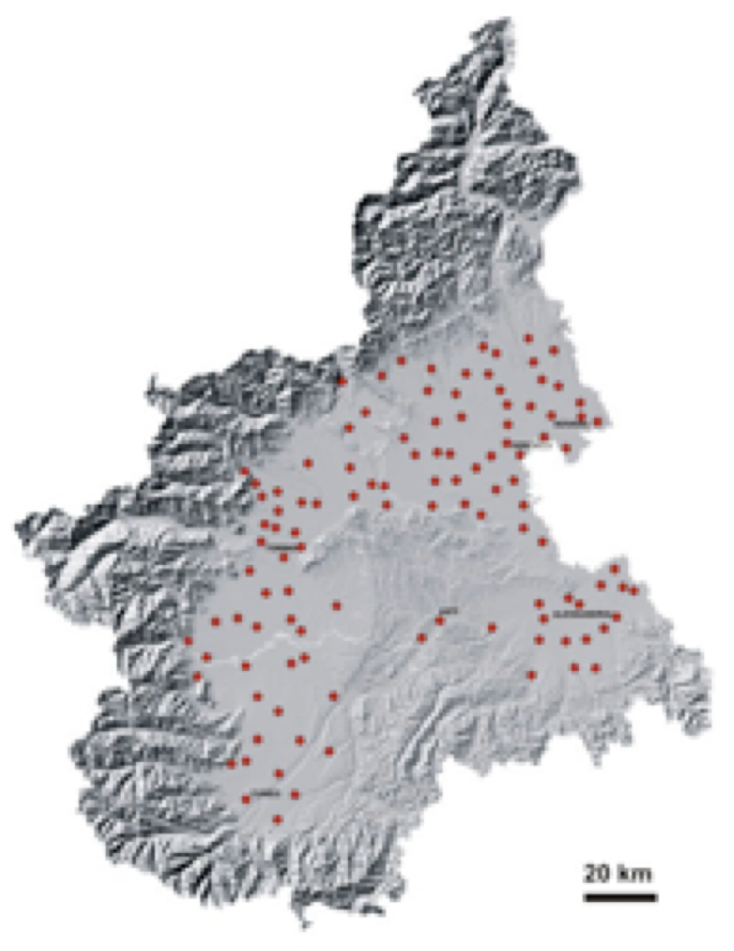

Fig. 1 -Piezometric monitoring network of Piedmont Region.

\section{THEORETICAL ASPECTS}

The partial differential equation which describes the heat transport by diffusion (conduction and advection) through an isotropic, homogeneous, characterized by planar and parallel layers, porous and fully saturated is described by Eq. (1). This equation that take into account the conductive heat flow, the radiogenic heat linked to endogenous sources and then the heat transfer for advection connected to groundwater flow in the aquifer.

$$
k \nabla \cdot(\nabla T)+A_{0}-\nabla \cdot\left(\Phi \rho_{w} c_{w} \vec{v}_{w} T\right)=\rho c \frac{\partial T}{\partial t}
$$

where: $T$ : temperature $\left({ }^{\circ} \mathrm{C}\right)$; $\Phi$ is the porosity of the material, $c$, $c_{w}$ : specific heats of saturated material and water $\left(\mathrm{Jkg}^{-1}{ }^{\circ} \mathrm{C}^{-1}\right)$; $\rho, \rho_{w}$ : densities of saturated material and water $\left(\mathrm{kg} \cdot \mathrm{m}^{-3}\right) ; k$ : thermal conductivity $\left(\mathrm{Wm}^{-1}{ }^{\circ} \mathrm{C}^{-1}\right) ; v_{w}$ : water specific discharge $\left(\mathrm{m} \cdot \mathrm{s}^{-1}\right) ; t$ : time $(\mathrm{s}) ; A_{0}$ : radiogenic heat in the time.

In the analysis of heat flows at limited depth, as considered in this research, it isn't necessary to take into account the deep geothermal gradient. So, we can then use the equation of propagation of heat in the form which it assumes in the absence of endogenous sources of heat (see $A_{0}$ in Eq. 1). With simplifying assumptions, we take into account the temperature variations in the vertical direction only, $\frac{\partial^{2} T}{\partial z^{2}} \gg \frac{\partial^{2} T}{\partial x^{2}}$ and $\frac{\partial^{2} T}{\partial y^{2}}$ and we consider the specific discharge uniform, $\nabla \cdot \mathrm{v}_{\mathrm{w}}=0$. So, the Eq. (1) can be simplified in the form Eq. (2)

$$
k \frac{\partial^{2} T}{\partial z^{2}}=\rho c \frac{\partial T}{\partial t}
$$

The differential equation thus obtained (a second order partial differential equation), Eq. (2), provides, among others, oscillating solutions representative of seasonal variations in which the temperature, because of the exponential term, gradually tends to stabilize in depth, until reaching an asymptotic behavior, with an approximately constant temperature value $T_{0}$ Eq. (3)

$$
T(z, t)=T_{0}+A e^{-z \sqrt{w / 2 \alpha}} \cos \left[w\left(t-z \sqrt{\frac{w}{2 \alpha}}\right)\right]
$$

where:

$\frac{k}{\rho c}=\alpha\left(\mathrm{m}^{2} \mathrm{~s}^{-1}\right)$ is the coefficient of thermal diffusion; $A$ is amplitude of the temperature oscillation; $w$ is the pulsation association with period of oscillation $\tau ; \gamma$ is the damping constant; $T_{0}$ is value of temperature at the "homoeothermic depth", a depth beneath it, the temperature is constant in the time (it is not influenced by daily and seasonal variation of the external temperature). The "homoeothermic depth" varies from a minimum of 20 meters in the northeastern and southeastern plains to a maximum of 25 meters in the northwestern and southwestern ones (Barbero et al., 2014).

$$
\begin{aligned}
& \text { Set } \gamma=\sqrt{\frac{\omega}{2 \alpha}} \text { we obtain Eq. (4): } \\
& \qquad(z, t)=T_{0}+A e^{-\gamma z} \cos (w t-\gamma z)
\end{aligned}
$$

The solution Eq. 4 shows that the temperature variation in the subsoil is an harmonic function whose amplitude $A$ decreases with increasing depth $z$, because of the "damping factor" $e^{-\gamma z}$.

\section{STATISTICAL ANALYSIS}

The problem is to determine a function that represents the relationship between two quantities $z$ (depth) and $T$ (Temperature), compatible with the theoretical solutions of the heat equation. Note some pairs of data $(z, T)$, interpreted as points in the plane, it is proposed to find a function (interpolating) which is capable of describe the relationship between the set of values of $x$ and that of the values of $y$. The numerical procedure by which occurs the adherence of data to a certain theoretical law through optimization of some parameters is called a procedure best fit. The easiest analytical procedure to check if the experimental data are or are not a certain theoretical law and at the same time extract the parameters from this trend is the "least squares method", which it is based on the minimization of the quadratic error. Assuming also that the measure of each $y_{i}$ value is governed by a Gaussian distribution with width $\sigma_{i}$ in order to determine the least squares function which best interpolates the measurements. The most reasonable function to describe the time average of the temperature $T$ at depth $z$ is (Eq. 5): 
A)

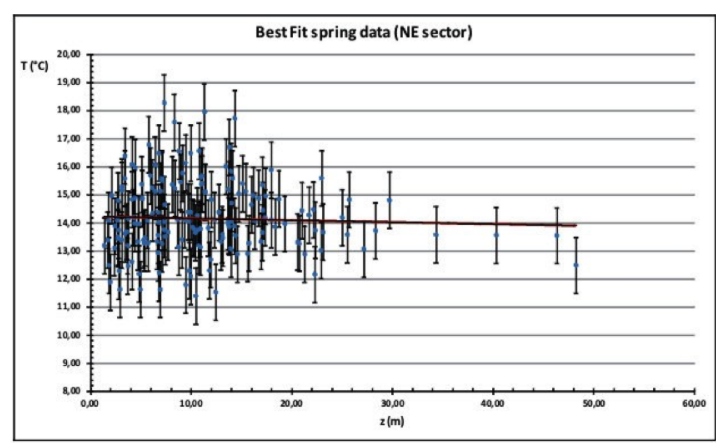

B)

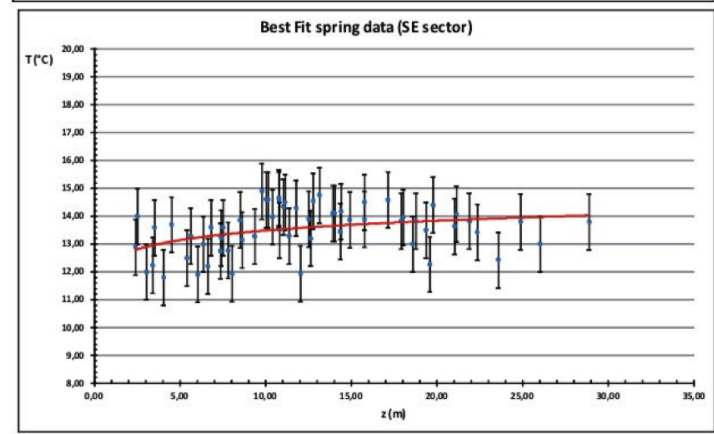

c)

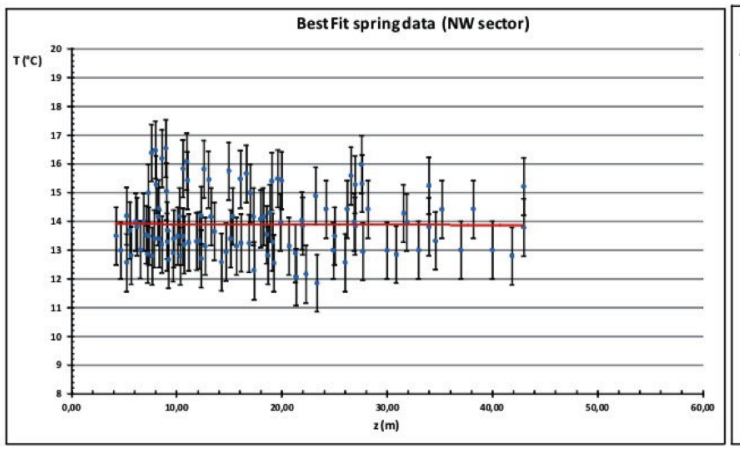

D)

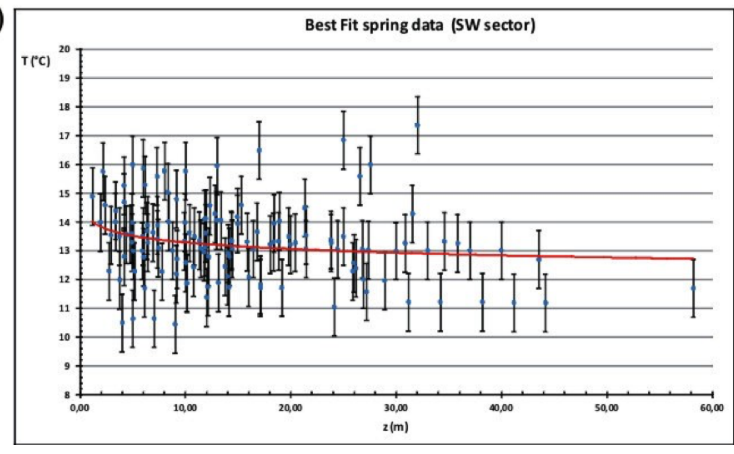

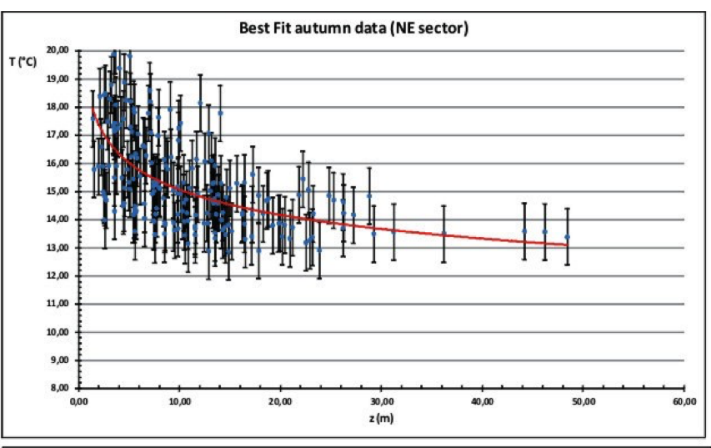
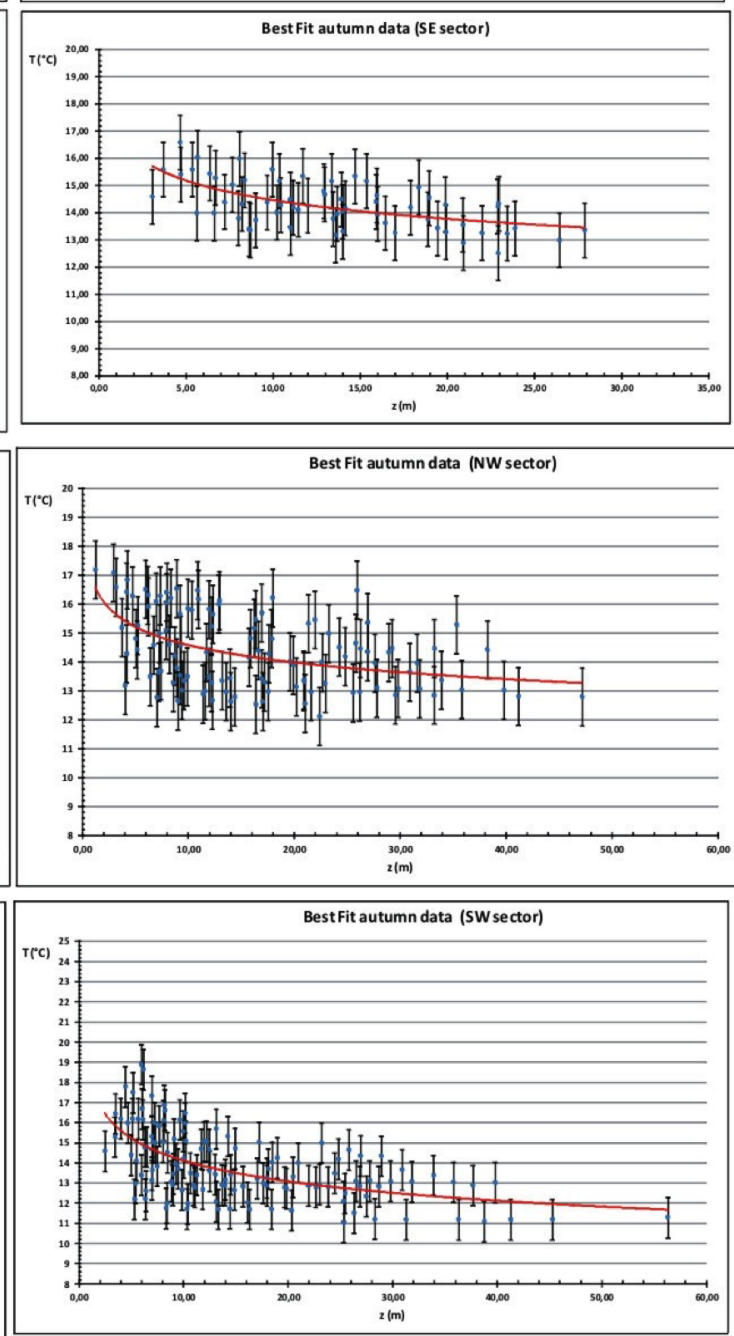

Fig. 2 - Best fit for spring and autumn data of the plain sectors.

$$
T(z)=T_{0}+a e^{-b z}
$$

Using the "least square method", the best values of the parameters $T_{0}, a$ and $b$ matching the thermometric data can be found.

\section{RESULTS}

Associating to spring and autumn data a statistical uncertainty on temperature $\sigma_{\mathrm{T}}= \pm 1.00^{\circ} \mathrm{C}$, we find a good agreement with the expected distribution (see Eq. 5):
NE SECTOR: Novara and Vercelli Po Plain (fig. 2A)

The equation for the spring and autumn data are respectively:

$\mathrm{T}(\mathrm{z})=(13.9225 \pm 0.1945)+(0.0564 \pm 0.0253) \cdot \mathrm{e}^{(0.0017 \pm 0.0006) \mathrm{z}}$ $\mathrm{T}(\mathrm{z})=(17.3906 \pm 0.1822)-(0.2496 \pm 0.0238) \cdot \mathrm{e}^{-(0.0038 \pm 0.0006) \mathrm{z}}$

The equation describing the time average of the temperature distribution in the aquifer can be approximated as:

$$
\mathrm{T}(\mathrm{z})=\left(15+0.15 \mathrm{e}^{-0.001 \mathrm{z}}\right){ }^{\circ} \mathrm{C}
$$


SE SECTOR: Alessandria Po Plain (fig. 2B).

The equation for the spring and autumn data are respectively:

$$
\begin{aligned}
& T(z)=(12.1768 \pm 0.4637)+(0.2795 \pm 0.0742) \cdot e^{(0.0092 \pm 0.0026) z} \\
& T(z)=(16.1939 \pm 0.4822)-(0.1372 \pm 0.0762) \cdot e^{-(0.0010 \pm 0.0026) z}
\end{aligned}
$$

The equation describing the time average of the temperature distribution in the aquifer can be approximated as:

$$
\mathrm{T}(\mathrm{z})=\left(14+0.20 \mathrm{e}^{0.004 \mathrm{z}}\right){ }^{\circ} \mathrm{C}
$$

NW SECTOR (Turin Po Plain) (fig. 2C)

The equation for the spring and autumn data are respectively:

$$
\begin{gathered}
T(z)=(13.9216 \pm 0.3767)+(0.0064 \pm 0.0409) \cdot e^{(0.0002 \pm 0.0004) z} \\
T(z)=(16.2504 \pm 0.2926)-(0.1541 \pm 0.0325) \cdot e^{-(0.0023 \pm 0.0007) z}
\end{gathered}
$$

The equation describing the time average of the temperature distribution in the aquifer can be approximated as:

$$
\mathrm{T}(\mathrm{z})=\left(15+0.80 \mathrm{e}^{-0.001 \mathrm{z}}\right){ }^{\circ} \mathrm{C}
$$

SW SECTOR (Cuneo and Southern Turin Po Plain) (fig. 2D) The equation for the spring and autumn data are respectively:

$$
\begin{gathered}
T(z)=(13.3023 \pm 0.2556)+(0.0197 \pm 0.0266) \cdot e^{(0.0004 \pm 0.0005) z} \\
T(z)=(16.4590 \pm 0.2226)-(0.2105 \pm 0.0251) \cdot e^{-(0.0027 \pm 0.0005) z}
\end{gathered}
$$

The equation describing the time average of the temperature distribution in the aquifer can be approximated as:

$$
\mathrm{T}(\mathrm{z})=\left(15+0.11 \mathrm{e}^{-0.0011 \mathrm{z}}\right){ }^{\circ} \mathrm{C}
$$

\section{CONCLUSIONS}

The temperature average values found for every plain sector are compatible with the solutions of the heat conduction equation in stationary boundary conditions. These preliminary results provide a statistically evaluation of the expected value of the groundwater temperature in the first 20-30 meters of the subsurface, with an uncertainty of $\pm 1.00^{\circ} \mathrm{C}$, where temperature are influenced by seasonal fluctuations; for depth greater of these ones, the temperature equations found (Eq. 6, 7, 8,9) are not valid because the temperature assumes a constant value according to the presence of the "homoeothermic depth". The method is being developing, in order to reduce the statistical uncertainty associated with the temperature measurements, and improving the calculated fits. Finally, the experimental methodology proposed may be adopted as a simple statistical method for the assessment of geothermal potential in a specific area hosting a shallow aquifer, where to know the temperature with a view to the exploitation of the water resource assessments for low-enthalpy geothermal purposes with GWHP systems is useful.

\section{REFERENCES}

Balsotti R. (2009) - Indagine piezometrica sui piezometri della rete di monitoraggio quantitativa regionale. Resoconto delle attività svolte, Arpa Piemonte.

Barbero D., De Luca D.A., Forno M.G., Lasagna M. \& Magnea L. (2014) - A statistical approach to the study of thermal data of shallow aquifer in Piedmont region (NW ITALY). Abstracts Book of DAMES 2014: 4th International Conference on Data Analysis and Modeling in Earth Sciences, Milano 6-8th October 2014.

Boni A. \& Casnedi R. (1970) - Note illustrative della Carta Geologica d'Italia alla scala 1:100.000, Fogli 69 e 70 "Asti e Alessandria", II ${ }^{\mathrm{a}}$ ed., Serv. Geol. It., Roma.

Bonsignore G., Bortolami G.C., Elter G., Montrasio A., Petrucci F., Ragni U., Sacchi R. \& Zanella E. (1969) - Note illustrative della Carta Geologica d'Italia alla scala 1:100.000, Fogli 56 e 57 "Torino e Vercelli", II ${ }^{\mathrm{a}}$ ed., Serv. Geol. It., Roma.

Bove A., Destefanis E., De Luca A.D., Masciocco L., Ossella L. \& Tunossi M. (2005) - Assetto geoidrologico della regione Piemonte. (Cd Rom). Idrogeologia della Pianura Piemontese, Regione Piemonte.

Forno M.G., Gattiglio M., Comina C., Barbero D., Bertini A., Doglione A.., Irace A., Gianotti F., Martinetto E., Mottura A. \& Sala B. (2015) - Stratigraphic and tectonic notes on the Villafranca d'Asti succession in type-area and Castelnuovo Don Bosco sector (Asti reliefs, Piedmont). Alpine and Mediterranean Quaternary, 28(1), 5-27.

Irace A., Clemente P., Natalicchio M., Ossella L., Trenkwalder S., De Luca D.A., Mosca P., Piana F., Polino R., \& Violanti D. (2009) - Geologia e idrostratigrafia profonda della Pianura Padana occidentale (Regione Piemonte). La NuovaLito, Firenze, pp 110.

Servizio Geologico d'Italia (1967) - Carta Geologica d'Italia alla scala 1:100.000, F. 44 Novara. 